Article

\title{
From Sustainable Development Goals to Sustainable Cities: A Social Media Analysis for Policy-Making Decision
}

\author{
Amal Marzouki ${ }^{1}$, Arbi Chouikh ${ }^{1} @$, Sehl Mellouli ${ }^{1, *}$ and Rim Haddad ${ }^{2}$ \\ 1 Department of Organizational Information Systems, Faculty of Business Administration, Université Laval, \\ Québec, QC G1V 0A6, Canada; amal.marzouki.1@ulaval.ca (A.M.); arbi.chouikh.1@ulaval.ca (A.C.) \\ 2 Higher School of Communications of Tunis, Université de Carthage, Ariana 2083, Tunisia; \\ rim.haddad@supcom.tn \\ * Correspondence: sehl.mellouli@fsa.ulaval.ca
}

check for updates

Citation: Marzouki, A.; Chouikh, A.; Mellouli, S.; Haddad, R. From Sustainable Development Goals to Sustainable Cities: A Social Media Analysis for Policy-Making Decision. Sustainability 2021, 13, 8136. https:// doi.org/10.3390/su13158136

Academic Editors: J. Ramon

Gil-Garcia, Mila Gasco-Hernandez and Tzuhao Chen

Received: 28 May 2021

Accepted: 11 July 2021

Published: 21 July 2021

Publisher's Note: MDPI stays neutral with regard to jurisdictional claims in published maps and institutional affiliations.

Copyright: (c) 2021 by the authors. Licensee MDPI, Basel, Switzerland. This article is an open access article distributed under the terms and conditions of the Creative Commons Attribution (CC BY) license (https:// creativecommons.org/licenses/by/ $4.0 /)$.

\begin{abstract}
The United Nations (UN) adopted the seventeen "Sustainable Development Goals" (SDGs) in early September 2015. One of these goals is SDG 11, which refers to the sustainable cities and communities. In this context, local governments face the challenge of aligning with this objective. As a result, they are increasing outreach to their organizational boundaries to involve citizens in policy making and strategy development, continually listening to citizens' voices. One of the methods citizens use to express themselves is social media. This paper will emphasize social media platforms and specially Twitter to explore the public discourse about cities in the context of SDG 11. We applied descriptive quantitative and qualitative analysis to analyze the tweets that include terms and hashtags referring to the SDG 11 . The data analysis process is composed of three major procedures: 1-Engagement analysis, 2-Trends based analysis and 3-Data Insights. Our results show that: 1-the COVID'19 pandemic negatively impacted users engagement towards SDG 11, 2-new technologies such AI and IoT are gaining more importance to help cities reach SDG 11, and 3-the SDGs are related and one SDG can impact other SDGs.
\end{abstract}

Keywords: tweets; engagement analysis; trends analysis; policy-making

\section{Introduction}

On 25 September 2015, the United Nations adopted by the member states during the General Assembly an ambitious international development agenda, comprising 17 Sustainable Development Goals (SDGs) and 169 targets. The SDGs for 2030 represent a determined plan for transformation over a 15 -year period. The 17 main SDGs cover a wide range of issues, from poverty, gender equality, water and sanitation, energy, sustainable cities, climate change, and peace. The SDGs encompass social, economic, and environmental reforms, targeting both developed and developing countries independently from their level of development [1]. The fulfillment of these objectives requires strong cooperation at international, national, and local levels. Scholars are investigating the interactions among energy, economy, climate, and land to develop integrated policies that better implement the SDGs [2].

The United Nations estimate that the world population will increase by $32 \%$ in 2050 compared to 2015, from 7.2 to 9.7 billion inhabitants [3]. The UN also predicts that until 2030 , over $60 \%$ of the world population is going to live in cities [4]. As a result, cities across the World will increasingly face the challenges to ensure the access to services with quality such as transportation, medical care, environment protection, and waste management, etc. Due to the major challenges that cities will face, one of the SDG focused specifically on cities which is SDG 11. SDG 11 aims to "make cities and human settlements inclusive, safe, resilient and sustainable" (https: / / www.globalgoals.org/11-sustainable-cities-andcommunities, accessed on 28 March 2021). This step is perceived as reflecting an increased awareness of the important role that cities can play for global development pathways [5]. 
As stated in [6], "the battle for the SDGs will be won or lost in cities". This research will focus on SDG 11 which has five topics, ten targets and 15 indicators, as shown in Figure 1.

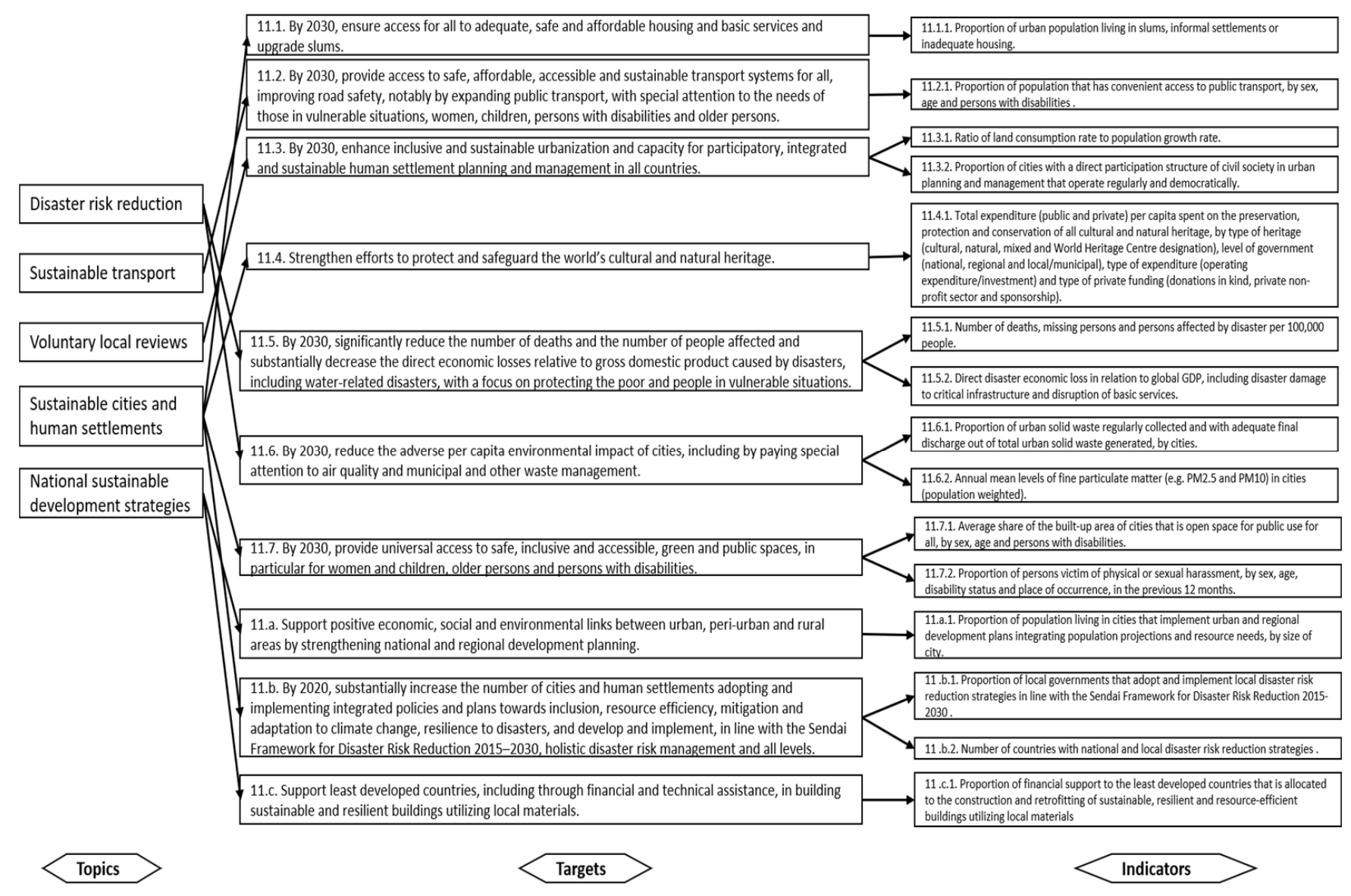

Figure 1. Topics, targets and indicators of SDG 11.

In fact, there is a significant scholarly debate about the SDGs in relation with sustainability and SDG 11, and the concept of sustainable cities are not an exception. In this context, scholars have been considering the "local" aspect of sustainability for a few decades by focusing on economic restructuring and social and the environmental justice [7]. For example, Kenworthy in [8] suggested that the urban governance and planning need to be reformed to reflect sustainability, by considering the threats that the environment is increasingly facing due to the transportation systems, waste, and energy consumption. Thus, he suggested that urban planning should be vision-oriented and involve reformist thinking with a strong community-oriented and democratic sustainability framework for decision-making. In this sense, there is a direct link between SDG 11 and sustainable cities, which refers to the potential of urban transformations to sustainability [9].

Given the challenges that cities are facing to meet the needs of the urban population, to address climate change, promote economic growth, and enhance social inclusion [10], a sustainable city could support the provision of efficient services, energy, and landuse [11]. This could be done through using green energies and technologies, recycling, smart land-use, and transportation planning [12,13]. Indeed, these are the main purposes of SDG 11, which answers the question "what should we do?" like the rest of the SDGs, despite this question not being as helpful as it might seem according to W. Easterly in [14]. However, there is a theoretical compromise that SDG 11 establishes a global urban policy position in a unified statement regarding the overall social, economic, and environmental functionality of cities and the urban system [15]. It deals with the theories acknowledging that responding to local contexts and stakeholder needs should be done through engaging diverse local partners to foster urban transitions [16-18]. 
As stated in [19], the theory of SD appeared in the 1980s and evolved over time to be part of the high-level political agenda, becoming an integral part of the agenda of governments. SD started with three pillars that were the economy, society, and environment. A fourth pillar has been introduced which is culture, institutions, or governance.

This paper focuses on the governance pillar. With the use of Information and Communication Technologies, governance can be extended to e-governance. E-governance is defined as "E-governance comprises the use of information and communication technologies (ICTs) to support public services, government administration, democratic processes, and relationships among citizens, civil society, the private sector, and the state." [20]. More specifically, the paper addresses the relationship between citizens and the government regarding SDGs. The city will look to the specific direction of communication from citizens to policymakers.

Policymakers in cities will have the responsibility to ensure that the development of their cities is aligned with SDG 11. As policy makers become more aware of the evaluation of cities-related development, they can increasingly account for citizens opinions to answer their needs and to develop new policies. For this purpose, policymakers should have the tools to catch citizen's opinions and/or feedbacks about sustainable cities. One of the ways that people use to express themselves is social media. Scholars argue that the use of IT and social media makes it possible and subsequently easier to get a comprehensive picture of public concerns and to identify the most important factors involved therein [21]. Consequently, our motivation is that social media-based SDGs discourse is increasing, and that we could explore useful information to help not only policymakers in designing their policies, but also scholars in developing methodologies and frameworks to analyze the social media data and translate them into policy headlines and directions.

We will use Twitter as a social media platform in this work. Specifically, this paper will answer the following research question: How do we identify relevant information related to the topics, targets, and indicators of SDG 11 to better inform policymakers? By answering this research question, we could help decision and policy makers to better assess the expectations and needs of their fellow citizens in terms of sustainable development. To do so, our research objectives are:

1. Analyze a set of tweets that refer to SDG 11 and that were posted between 1 September 2015 and 31 December 2020;

2. Measure the Twitter users' engagement, identify the trending hashtags, determine how the SDG 11 topics evolved overtime, and explore the insights resulting from the identified trends and the SDG 11 topics; and

3. Inform policymakers with the identified relevant information from objectives 1 and 2 .

This paper is structured as follows: Section 2 summarizes the research gap by presenting an overview of the literature on sustainable cities in the context of SDG 11. Section 3 explains the methodology and presents the data analysis process of the study. Section 4 details the research results. Section 5 presents the limitations and Section 6 concludes this study.

\section{Research Context: Towards Sustainable and Participatory Cities}

\subsection{Making Larger Cities: Several Challenges to Be Addressed}

As stated, the UN predicts that until 2030 , over $60 \%$ of the world population is going to live in cities [4]. Indeed, cities need to cope with such growth. They are facing several challenges to develop powerful bases for their day-per-day activities by enhancing their urban, administrative, and socioeconomical capacities. To this end, policy-makers will need to improve their political decision-making processes, build the public awareness, increase their economic competitiveness, and assess the ways in which environmental and social issues are conceptualized and their solutions determined [22].

In this sense, significant efforts have been spent by scholars, practitioners, and government agencies to develop frameworks to enhance cities ecosystems and monitor their growth in a continuous improvement process. In several urban areas, indicator systems 
have been developed and adopted by decision-makers and managers to implement and monitor their plans. Though, cities need a "new managerialism" approach [23] based on deep reforms of the public management of city services. Doing so, cities should be more efficient, effective, transparent and value for money [23].

\subsection{SDG 11: Objctives for Inclusive, Resilient and Sustainable Cities}

Cities will play a critical role in advancing progress towards global sustainable development [15] specifically with SDG 11 [24]. Through the implementation of this goal (i.e., targets and indicators), cities are expected to be inclusive, resilient and sustainable by 2030 . SDG 11 is considered as a "path breaking" that guides the member states to bring social inclusion and environmental sustainability together under a "balanced and integrated approach to urban sustainability monitoring" [25].

Several studies state that SDG 11 has fit with the scholarly debates referring to sustainable cities since the 1950s [26]. Most of these studies focused on the aspect of urban development as it has become one of the major policy issue for countries around the world due to rapid growth of the urban population $[13,16,18,26]$. Meanwhile, other studies focused on the socio-economic aspect [27] considering that cities are important generators of wealth, employment and productivity growth and often quoted as the "engines of their national economies", especially for the metropolitan regions. Besides urban development and socio-economic aspect, a city can also be considered as an "artifact environment" where the quality of life and environmental concerns undermine all advantages associated with agglomeration economies. Hence, different theories and policies aimed to drive the economy towards a "sustainable economy" [12]. In fact, sustainability at large could be perceived as "a process of change in which the exploitation of resources, the direction of investments, the orientation of technological development and institutional changes are made consistent with future as well as present needs" [28]. As cities and urban growth are at the core of such development [29], there is a compromise that urban planning should consider social, economic and environmental dimensions to ensure them competitiveness and their sustainability" $[9,11,18]$. Consequently, the discussion about sustainable development with regards to cities has caught a considerable scholar and official recognition where the terms "sustainable cities" and "sustainable human settlements" were much in evidence [30]. This discussion is in the core of SDG 11 that scholars consider as a way to distinctly allude urban development [5] and to give cities the main resources to operate a major development [29]. However, the correlation between building sustainable cities through sustainability protocols and the pursuit of SDG 11 targets is still less discussed in the literature despite the adoption of this goal [29]. For instance, the discussions on how to integrate policies and plans that fit with the targets and the indicators of the SDG 11 are continuously investigated [24,29].

Governments, including cities, are spending efforts to develop, implement, and monitor strategies for SDG 11 to transform cities and communities to sustainability. This transformation cannot be neither understood nor addressed by a single entity. It becomes imperative to bring together organizations from business, government and non-profit sectors to collaborate via a multi-stakeholder partnership [31]. In other terms, this participatory approach of implementing and monitoring the SDGs and particularly SDG 11 could contribute to the community and help to address local economic, social, and environmental concerns.

In this paper, we adopt the integrated information ecosystem (Figure 2) as a theoretical background. In this ecosystem, there are three spheres that are interrelated and that influence the implementation of SDGs in cities [32]: the sustainable sphere, the political sphere, and the administrative sphere. In the sustainable sphere, stakeholders, across multiple levels and sectors, seek to define sustainability and set targets by focusing on the most pressing concerns. The political sphere represents the place where debates related to SDGs take place to set new policies/priorities/rules. Finally, the administrative sphere focuses on the execution of the decisions taken in the political sphere. This paper will focus 
on the sustainability sphere. In this context, cities need to have the capacities to capture what the stakeholders are discussing in the sustainability sphere to highlight the most pressing concerns.

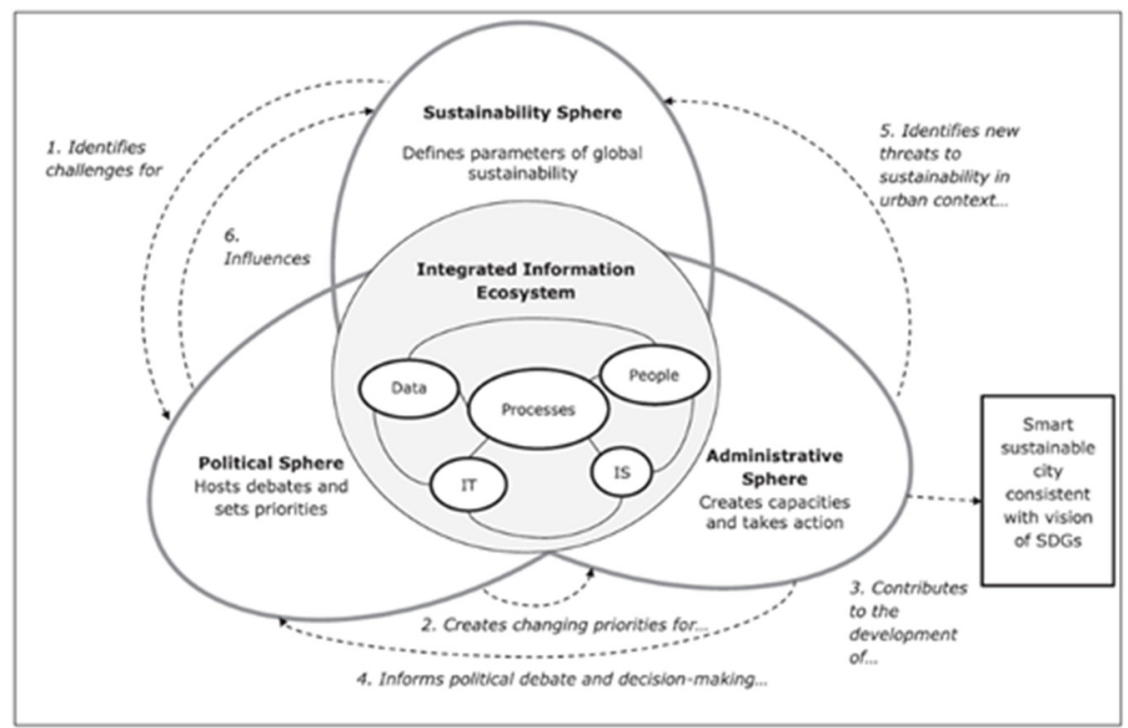

Figure 2. Model of an integrated information ecosystem for smart sustainable cities [12].

\subsection{Social Media as a Valuable Mean of Implementation and Monitoring}

Saner et al. in [33] suggest that the SDGs "concrete attainment" remains unclear, incomplete, and requires micro and macro dimensions for monitoring. They state that the monitoring should be participation-based and inclusive and has to be considered as an integral part for managing the SDGs implementation process to bring transparency and accountability to the process. In addition, the United Nations Development Group recognizes that to ensure accountability and tackle inequalities "more, better and new types of data are needed", with a focus that should no longer be limited to national aggregates, but also on disaggregated data that consider the "user concerns" [34]. As a result, there is an important need to engage citizens and non-profit organizations for a "citizen-driven" policy making [35].

Recently, with the evolution of IT tools and social media specifically, new and innovative ways of participation, co-design, and monitoring are emerging [36-38]. This emerging involvement is referred to as electronic participation (e-Participation), online civic engagement or digital coproduction [39-41]. Boudjelida et al. in [42] found that social media platforms are the most used tools for IT based citizen engagement. The key factor is the "democratizing power" of social media that allows citizens and government to raise the profile of their work and to clarify their societal contributions in a way that is unfiltered by the editorial decisions of traditional media [43]. It provides large channels of communication with significant affordances that embed deep interaction between users [44]. Hence, social media platforms can be considered a link between the sustainability sphere and the political sphere and are a valuable source of information to policymakers in the context of SDGs.

\subsection{Exploring the SDG 11 Insights from Twitter Data}

Citizens use social media platforms, like Twitter, to express their concerns about several issues. With the inherent strong dissemination capacity of social media, citizens can influence public opinion $[45,46]$. Many users are specifically interested in topics that refer to the challenges cited in the SDG 11. Our research focuses on the Twitter platform as a mean to collect what is being said about issues related to SDG 11. Twitter is a massive social networking site and microblogging platform on which registered users post and interact 
with messages known as "tweets" [47]. The impact of Twitter has been demonstrated in several contexts such as political communication [48], crisis and disaster detection and management [49], brand communication and marketing [50], and healthcare [51].

By extracting and analyzing the SDG 11 related data posted in Twitter, we examine the trends of the public discourse and provide insights and actionable research model that could help cities policymakers implement and monitor the SDG 11 considering its topics, targets, and indicators.

\section{Methodology}

In general, social media data, including Twitter data, can be classified into structured and unstructured data $[48,52]$. The structured data (i.e., identified also as metadata) compromise the user's information (e.g., name, description, spatial, temporal, etc.) and the content information (e.g., number of likes, retweets, mentions, etc.). The unstructured data is related to the "user-generated" textual content that are tweets, replies and comments.

The structured data is mainly quantitative (i.e., descriptive) and related to the usersactivity. Hence, it could be used mostly to measure the degree of engagement of users. We identify this approach as the "engagement analysis". The unstructured data allows exploring "qualitatively" the user-generated content to monitor and detect trends $[48,53]$. The trends can be combined with the structured data, in particular the temporal data (i.e., the date of creation of tweets) to investigate the evolution of these trends over time. The evolution of topics and trends over time is called "trends analysis". Finally, we can make an in-depth view on the data to see the links that may exist between pieces of data [54]. We identify this analysis as "data insights". So, our data analysis is based on these three types of analysis: engagement analysis, trends analysis, and data insights.

\subsection{Data Preparation}

Before analyzing the data, we first need to prepare it. Data preparation is conducted in two steps that we present hereafter: data collection and data pre-processing.

\subsubsection{Data Collection}

One of the major advantages of Twitter is that it provides Application Programming Interfaces (APIs) that allow third-party applications to connect to their servers and extract tweets data and meta-data. One of these applications is the Representational State Transfer (REST) API, used to retrieve past tweets matching established criteria such as topics, keywords, and users, within a search window [52]. Depending on the purposes, the data tracking approaches through the Twitter API could be (1) self-involvement approach, where individuals and institutions can have all tweets collected that contain their name (i.e., either as simple keyword or hashtag); (2) Keyword/topic-based approach where the collection of tweets is based on keywords or hashtags or topics to catch the opinions and/or the feedbacks about certain topics; and (3) actor-based approach where the collected tweets refer to specific users [48,55].

We will focus in our study on the keyword/topic- based approach, where the data related to the SDGs is collected iteratively (i.e., since 2015), as we are interested in exploring what people are discussing about the SDG 11. So, we first collected tweets about the SDGs in general and then extracted the subset of tweets about SDG 11. The tweets related to SDGs have been collected iteratively, using the keyword "SDGS" in the window time between September 2015 and December 2020. We collected 2,486,639 tweets. Once these tweets collected, we pre-processed them to identify the tweets related to SDG 11.

\subsubsection{Data Pre-Processing}

Once the data is collected, it needs to be pre-processed before extracting the tweets related to SDG 11. In the pre-processing phase, we went through two steps: data standardization and tweets filtering. 


\section{Data Standardization}

First, we considered only unique and distinct tweets. Doing so, our new dataset is composed of 877,381 tweets out of 2,486,639 tweets. Second, we standardized the 877,381 tweets. In fact, a tweet is a combination of alphanumeric text combined with symbols with a maximum length of 280 characters [56]. A tweet can contain abbreviations, slang terms, acronyms, links to external users or hashtags. Hence, the content can be noisy, unstructured and may contain unnecessary tokens that do not have necessarily a semantic significance [57]. In our case, we focused on four elements that need to be tackled to standardize our dataset: emojis, retweets symbols, @ mentions, and links. We decided to delete Emojis, the retweet symbols (i.e., RT), mentions (@) and links since these symbols will not bring any additional information in our analysis. Moreover, we converted all the tweets to lowercase to avoid duplication and to bring the tweets in a consistent form [58]. Third, we classified tweets by language. We notice that most of the tweets are written in English. As a result, we keep only the tweets that are written in English to have 719,299 tweets out of 877,381 tweets as a final initial dataset for this study.

\section{Data Filtering}

Once the tweets are pre-processed, we extracted the tweets related to SDG 11. To this end, we build a set of relevant hashtags related to SDG 11 that will be used to filter our dataset. These hashtags have been identified using three sources. The first source is the website "best-hashtags.com". The second source is the literature [59]. The third source is a set of potential hashtags that we build from the description of SDG 11, including the general description of SDG 11, the descriptions of the topics and the description of the targets, as provided by the UN. To this end, we used two algorithms: Rapid Automatic Keyword Extraction (RAKE) [60] and TopicRank [61]. We used the two algorithms because they don't provide the same result. So, to be exhaustive, we combined the two sets of keywords provided by the two algorithms. A keyword can be a single word or a combination of words. If a keyword is a combination of words, we generated all potential possible hashtags to refer to this keyword. For example, if we have air pollution as a keyword, we generate two hashtags: airpollution or pollutionair. Doing so, we have a new list composed of the keywords having only one word and all the combination of keywords. As a result, we got an overall list of 99 hashtags from the three sources that refer to SDG 11 and that we used to filter the initial dataset. Based on this list (see Appendix A), we found that there are 31,157 tweets from the initial dataset that refer to SDG 11.

\subsection{Engagement Analysis}

The engagement analysis is applied on the metadata. We establish the following metrics to measure the engagement:

- $\quad$ the frequency of tweets over time: depending on the type of the posted tweet, as a tweet can be "organic" (original for its holder) or "retweet" (retweeted by other user) or "reply" (the replies appear at the user timelines);

- the most active users: to explore the users that are the most interested in SDG 11 in terms of characteristics and involvement. As a result, it is possible to monitor the influencers or the potential influencers regarding the frequency and the quality of the content that they generate $[48,55]$.

\subsection{Trends and Topics-Based Analysis}

We aim through this analysis to monitor the trends and the topics from the collected data.

\subsubsection{Trends Analysis}

Trends analysis provides an overview on how the discourse evolved over time. To inform about this discourse, we based our analysis on the hashtags that were used in the tweets. In the dataset, we distinguish two types of hashtags: predefined hashtags and 
combined hashtags. The predefined hashtags are the hashtags in the list of the 99 hashtags used to filter the dataset (resulting from the Data filtering step).

The combined hashtags are those used in the dataset and that are not in the list of the 99 hashtags. Since we aim to provide a better understanding about how SDG 11 discourse evolved over time, the predefined hashtags were not used in this analysis since we know that they are used in the 31,157 tweets. So, to detect new and trending "insights" about the SD11, we based our analysis on the "combined hashtags". For example, as depicted in Figure 3, "\#cities" is a predefined hashtag and "\#neighbourhoods" is a combined hashtag.

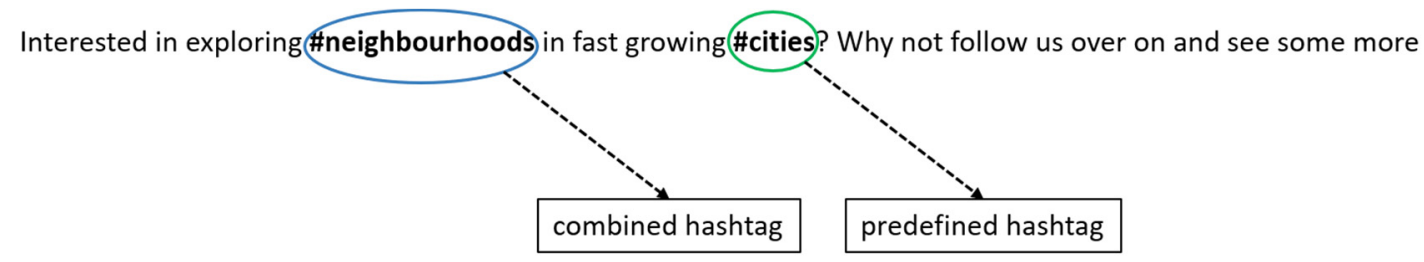

Figure 3. Example of predefined and combined hashtags.

Indeed, the combined hashtag provides new information to understand that the tweet is associated with communities and could be interpreted to show the importance of the involvement of neighborhoods in the growth of cities.

\subsubsection{Topics Analysis}

Topics analysis will be based on the topics of SDG 11. Doing so, we can inform how the discussion about each topic has evolved over time since policymakers might be interested to know the topics or issues that were discussed and how such discussions took place [48]. When we conducted our analysis, SDG 11 has five topics that are: disaster risk reduction, sustainable transport, voluntary local reviews, sustainable cities and human settlements, and national sustainable development strategies. As of May 2021, there are only four topics; the topic "voluntary local reviews" has been removed. Even though this change has occurred, it doesn't impact our methodology or our results interpretation.

The aim of the topics analysis is to identify the tweets that are related to the topics. To classify the tweets regarding to the five topics, we used a three-step approach:

1. First, for each tweet, we extracted its hashtags and then removed the \# symbol.

2. Second, for each topic, we looked at its description as provided in the UN website. To enrich the description of each topic, we looked also at the description of each target related to the topic as provided in the UN web site (http:/ / metadata.un.org/sdg/11 ?lang=en; accessed on 28 March 2021). From the combination of descriptions (topic and topic's targets), we extracted the keywords that describe the topic as we exactly did in the data filtering step but applied to each topic's enriched description. In doing so, we have a new list composed of the keywords having only one word and all the combination of words. This list is a sub-list of the predefined hashtags since the descriptions of the topics and the targets have been used to develop the predefined hashtags. Table 1 provides the list of related hashtags to each topic.

3. Third, we classified each tweet with regard to the topics. To this end, we based our classification on the predefined hashtags of each tweet since each tweet has at the minimum a predefined hashtag (filtering step), and that the list of hashtags related to the topics is a subset of the predefined hashtags. Doing so, we were able to associate the hashtags with the topics. Consequently, we've been able to associate the tweets having these hashtags with the topics. We mention that there are tweets that have hashtags that don't match the list of topics' hashtags. These tweets have not been classified in one of the topics. 
Table 1. SDG 11 topics and their main hashtags.

\begin{tabular}{|c|c|}
\hline Topic & Related Hashtags \\
\hline $\begin{array}{c}\text { Disaster risk reduction } \\
\text { (https:/ / sdgs.un.org/topics / disaster-risk-reduction; } \\
\text { accessed on 28 March 2021) }\end{array}$ & $\begin{array}{l}\text { \#ecodesign } \\
\text { \#urbanenvironment } \\
\text { \#airpollution }\end{array}$ \\
\hline $\begin{array}{c}\text { Sustainable transport } \\
\text { (https://sdgs.un.org/topics/sustainable-transport; accessed } \\
\text { on } 28 \text { March 2021) }\end{array}$ & $\begin{array}{l}\text { \#urbanmobility } \\
\text { \#roadtransport } \\
\text { \#publictransportation }\end{array}$ \\
\hline Voluntary local reviews * & $\begin{array}{l}\text { \#localgovernance } \\
\text { \#localgov } \\
\text { \#municipality }\end{array}$ \\
\hline $\begin{array}{l}\text { Sustainable cities and human settlements (https: / / sdgs.un. } \\
\text { org/topics / sustainable-cities-and-human-settlements; } \\
\text { accessed on } 28 \text { March 2021) }\end{array}$ & $\begin{array}{l}\text { \#urbandesign } \\
\text { \#affordablehousing } \\
\text { \#urbanpopulation }\end{array}$ \\
\hline $\begin{array}{c}\text { National sustainable development strategies } \\
\text { (https://sdgs.un.org/topics/national-sustainable- } \\
\text { development-strategies; accessed on 28 March 2021) }\end{array}$ & Hashtags non retrieved \\
\hline
\end{tabular}

\subsection{Data Insights}

There are different methods to visualize data for analysis and interpretation purposes such as word-clouds, histograms and matrices [48,52,62]. In addition to these techniques, there are also bigrams [62]. Bigrams are techniques to visualize links between words and to what extent the words have been used together. Bigrams will provide a semantic view and a better understanding of the data. Policymakers will have a deeper understanding of people's opinions and interests about the SDG 11 related topics.

Bigrams can be represented as a network where the vertices represent the words and the edges represent the weight of the co-occurrence [48,52]. We build the bigram based on all the data in the tweets. To do so, we removed the stop words and kept all the other words including the predefined and combined hashtags. In our bigrams, after several tests, we found that a word has to be in the bigram if it has occurred more than 150 times. All the other words that occurred less than 150 times are not included in the bigram.

\section{Results}

In the following section, we present and emphasize the results of our research.

\subsection{Engagement Analysis}

In the engagement analysis, we provide the frequency of tweets over time and the list of active users.

\subsubsection{Tweets Frequency}

As we mentioned previously, our dataset is composed of 31,157 tweets related to SDG 11. As can be observed in Figure 4, the public discourse about SDG 11 started in 29 September 2015. 
Frequency of tweets with SDG 11 hashtags by year

29 September 2015 to 30 December 2020

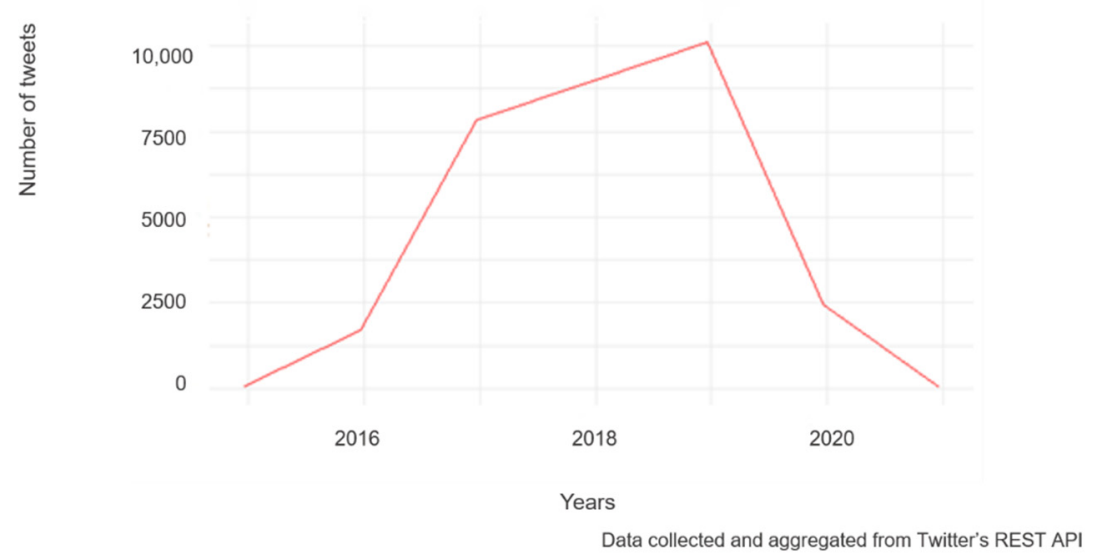

Figure 4. Frequency of tweets related to SDG 11 between September 2015 and December 2020.

Figure 4 shows that the peak of tweets was reached in 2019. However, it has experienced a significant drop since the beginning of 2020. This could be explained by the global health crisis of COVID-19, which dramatically caught the interest of Internet users, including tweeters. This result confirms the theoretical and the empirical studies suggesting that since the beginning of 2020, COVID-19 has gained significant attention and has been on the top of social media trends including Twitter $[63,64]$. Figures 5 and 6 show the rate of tweets, retweets, and replies and their evolution over time. We can observe that $54.2 \%$ of tweets are organic, $41.57 \%$ are retweets, and only $4.21 \%$ are replies. A high number of retweets indicates that the information about this subject is circulating rapidly on social media. A low number of replies may indicate that there are not well-developed interactions between the users on twitter for SDG 11. We observe that there is a high interest for the organic tweets with a ratio of $41.57 \%$ of retweets. This shows a high interest of people to tweets related to SDGs, which is aligned with the literature that states that Twitter is one of the main channels where people express this interest in the environment, society, and health $[21,65]$.

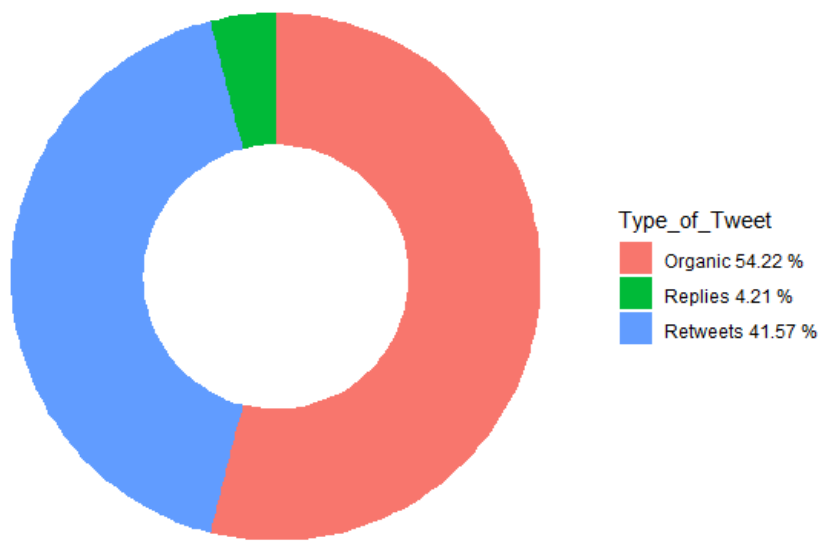

Figure 5. Ratio of organic tweets, replies and retweets related to SDG 11 of our dataset. 


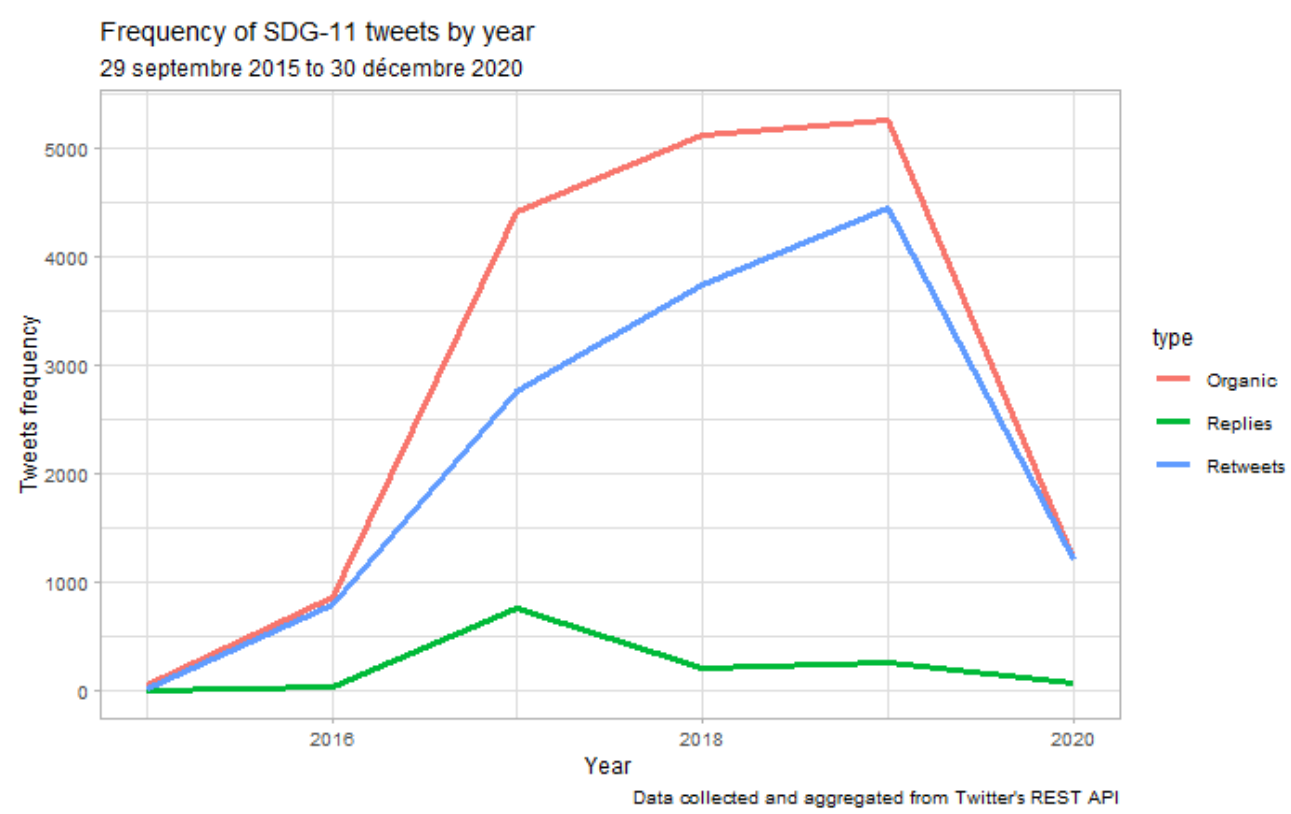

Figure 6. Frequency of organic tweets, replies and retweets by year.

\subsubsection{Active Users}

Figure 7 represents the top 10 most active users (or accounts) in terms of tweets, retweets, and replies. From this figure, we can see that the 10 most active accounts in terms of organic tweets each produced between 370 and 65 tweets over the 6 years. In terms of retweets, the top 10 retweeting accounts each produced between 648 and 73 .
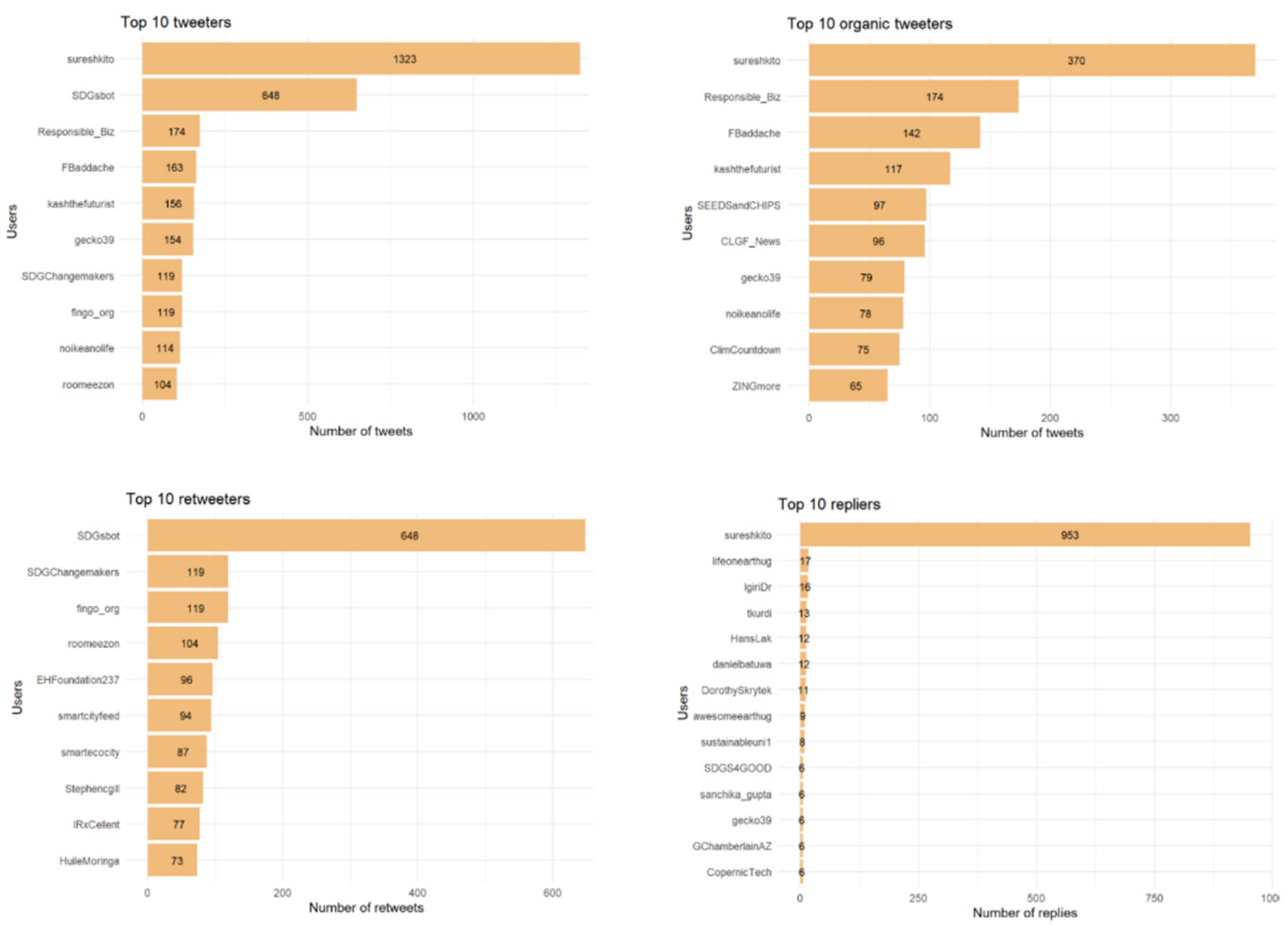

Figure 7. Most active Twitting users. 
Finally, the top 10 repliers show that there is mainly one account very active to engage in discussion and replies to other tweets. This reflects the low number of replies compared to the organic tweets and retweets. We observe that the creators of tweets are individuals or non-UN representatives than UN bodies and representatives. It may be positive if the UN and the official government representatives are more active to tweet about SDG 11 to create a momentum of discussion around this goal for education and awareness purposes. This recommendation is supported by Domínguez et al. in [66] who studied the extent to which Twitter could be a tool to raise the awareness and educate people to improve cities' living conditions towards more active and sustainable post-covid cities. The authors identified the top ten influential and active accounts, and show that there is a "new conscious audience" that could be more aware about social, economic, and environmental issues and concerns through Twitter active users. The study also shows that educational institutions, local organizations, NGOs, neighborhood associations, and individual accounts could raise the public awareness about local issues when they are more active. This observation of Dominguez et al., supports our recommendation that UN bodies and governmental institutions need to be more active on Twitter regarding SDGs.

\subsection{Trends and Topic Analysis}

\subsubsection{Trends Analysis}

For the trends analysis, we conducted two analyses: a global analysis and a time-based analysis. Figure 8 presents the global evolution of the trends combining all the tweets of the last 6 years. We can see that the two most cited combined hashtags in these 6 years are related to the climate action (climateaction) and health (CSR).

\section{Global Distribution of the combined hashtags}

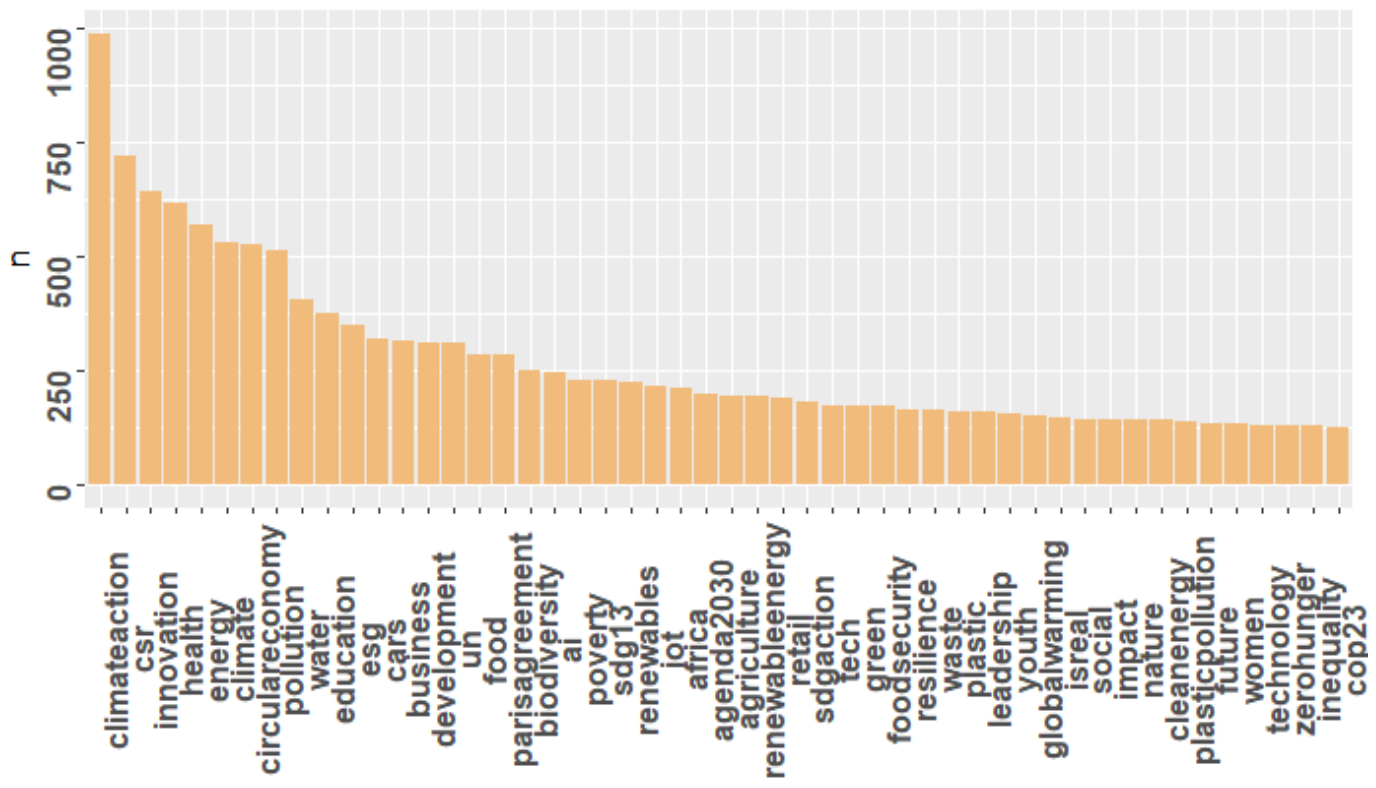

Figure 8. Distribution of the combined hashtags.

Figure 9 investigates the evolution of the trends over time to observe how the discourse evolved over time around SDG 11. We observe that there are specific hashtags that we can find each year such as \#CSR, \#climatereaction, or \#innovation. However, we observe other hashtags that were used only for a specific year such as the hashtag \#cop21 in 2015 since it was the year when the Paris Conference on Climate Change took place. We also observe the importance of hashtags related to artificial intelligence, IoT, or innovation that have been attracting more and more attention when talking about cities. For example, the hashtag AI, which ranked 15th in 2018, continued to grow to take the 8th place in 2020. 


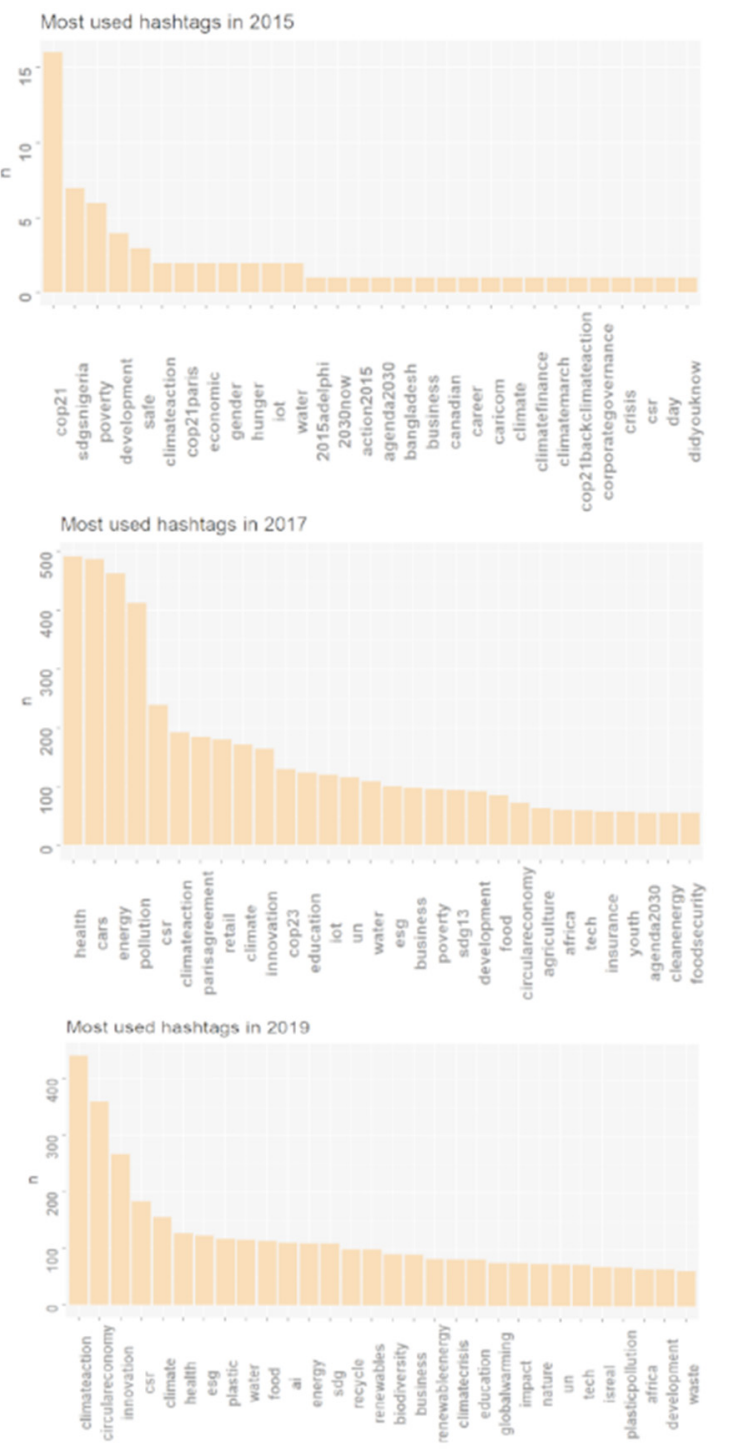

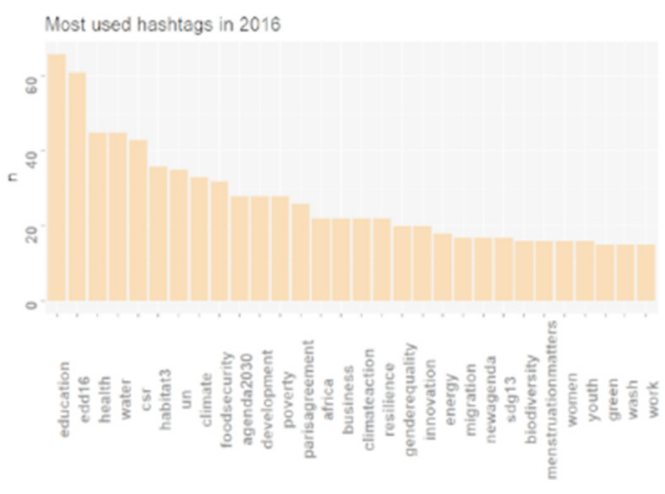
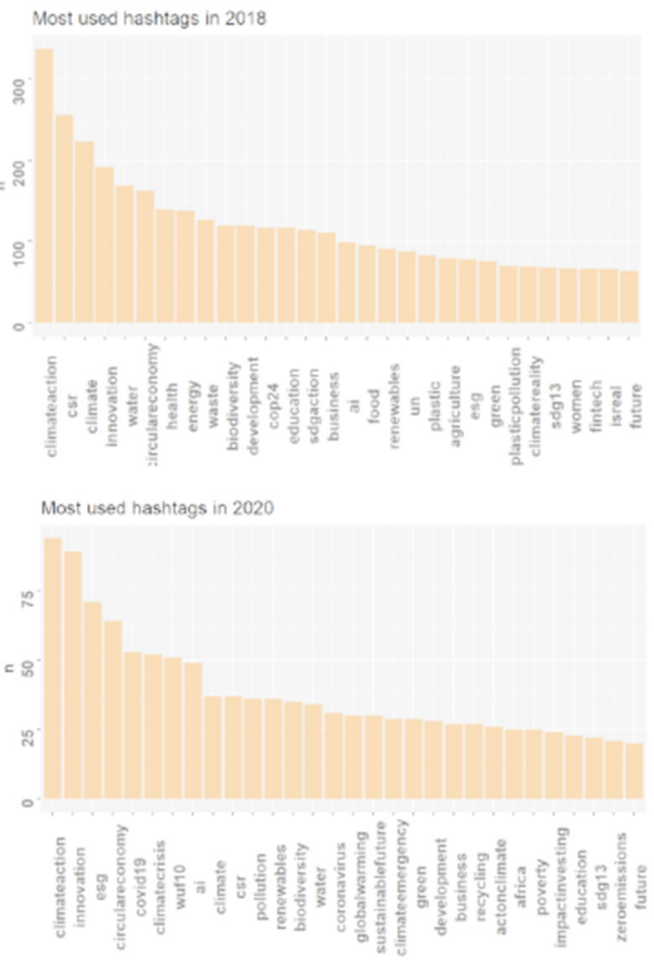

Figure 9. Frequency of Most used combined hashtags per year from 2015 to 2020.

Pilař et al. in [65] analyzed the discourse related to sustainability published in Twitter with the aim to identify the main topics through hashtags significations. The key hashtags that they identified refer to innovation, climate change, corporate social responsibility, technology and energy. These findings fit almost with our results, as the key hashtags that we identified in our dataset are related also to climate change, csr, technology and energy. However, we identified other key hashtags that refer to health and food security. Regarding the list of the most frequent hashtags retrieved in [65], there are numerous hashtags that we eliminated from our dataset, as we consider them as general and could be useful for filtering and classification purpose, such as \#sustainability, \#sdgs and \#globalgoals. In addition, our study considers the sustainable development goals with a focus on SDG 11, so it could be understood that we have key hashtags (i.e., like health, education, leadership, etc.) which refer mainly to public services or local issues in cities that could be not identified in more general studies. Moreover, Kumar et al. in [67] suggest that cities are playing an important role in the environmental development and that they could have a major contribution on climate change. In our study, as the hashtag "\#climate action" is the most frequent, we believe that more local consideration toward climate change is needed in urban planning to ensure the sustainability of cities which could contribute on the global sustainability $[17,30]$. 


\subsubsection{Topics Frequency}

We classified the tweets regarding the SDG 11 topics: Disaster risk reduction, sustainable transport, voluntary local reviews, sustainable cities and human settlements, and national sustainable development strategies. Figure 10 represents the evolution of SDG 11 topics over the last 6 years. We observe that the most discussed topics are disaster risk reduction, sustainable cities, and human settlements. However, we observed that little has been discussed about sustainable transport or voluntary local reviews, and that there is no discussion about the topic of national sustainable development strategies.

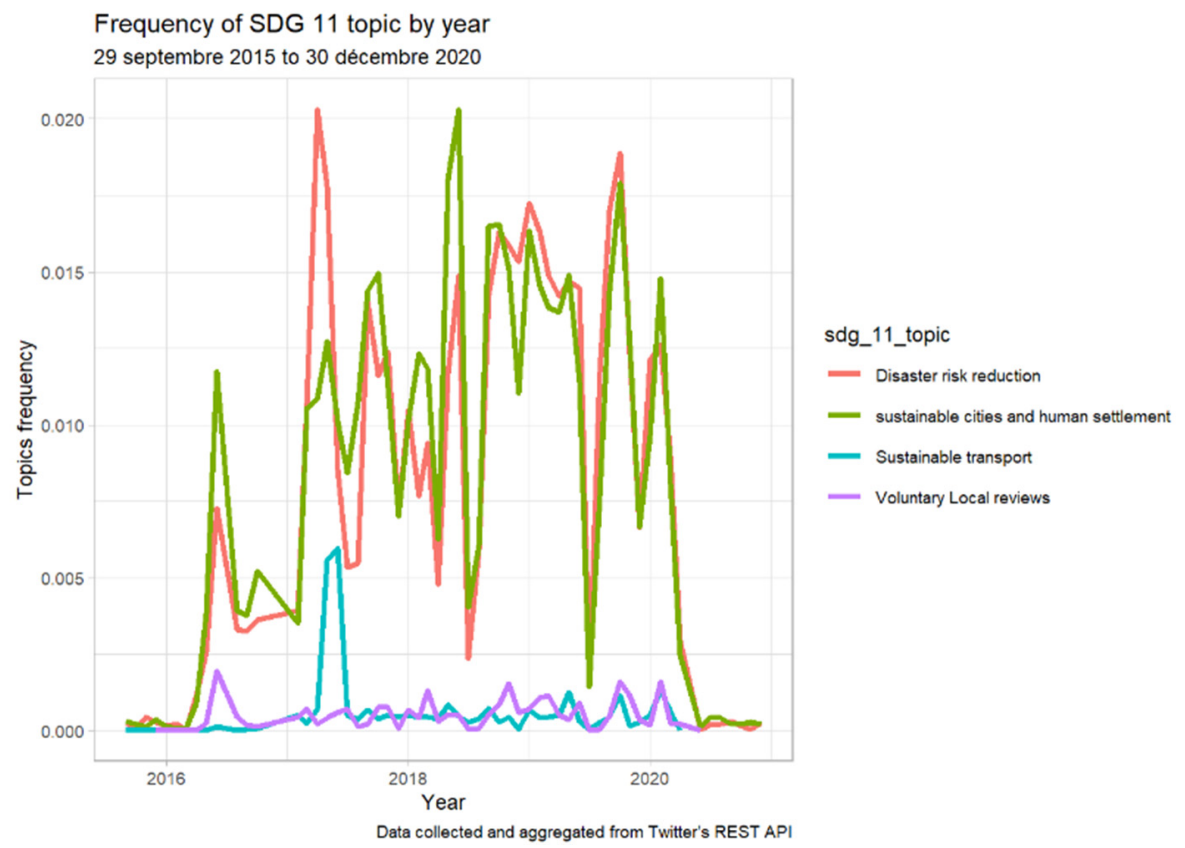

Figure 10. Evolution of the SDG 11 topics over time.

When looking to the literature, we haven't found any study that classified tweets, as we did, regarding the five topics related to SDG 11 as published by the UN. However, we found several studies in the literature that depicted key trends of SDG 11 or sustainable cities discussed on Twitter. First, we observed that some of these studies referred to climate change and energy issues that refer to the topic "Disaster risk reduction" $[65,66,68]$. In the same vein, there are other studies that refereed to habitation, health, food, security and other urban and social issues $[69,70]$ that are related to the topic "Sustainable cities and human settlements". Finally, the study of Pilař et al. in [65] highlighted hashtags related to "Sustainable transport "that are innovation and energy. For the fourth SDG 11 topic, the voluntary local reviews, Haro-de-Rosario et al. in [71] showed that Twitter and Facebook are becoming major channels of online interactive participation and that local governments are increasingly seizing this opportunity to enhance citizen engagement in political and social issues. They showed also that Twitter is less preferred in comparison to Facebook as a mean of citizens' participation in local governance. This could confirm our finding in Figure 10, showing that the topic "voluntary local reviews" is less discussed than the other SDG 11 topics. In addition, our observation for the fourth SDG 11 topic is aligned with our observation for the most active users where UN agencies and governments are not very active.

On the other hand, we notice a considerable decrease in the level of the interaction on all the topics of the SDG 11 at the beginning of 2020. As mentioned above, this can be argued by the propagation of the global pandemic COVID-19 where people became more focused on the pandemic and its consequences around the world. This observation is well aligned with our observation at the tweets frequency that decreased in 2020. 


\subsection{Insights Analysis}

As shown in Figure 11, we can see that the most used words in the bigram are related to the environment as the pollution and the climate change, which confirms our findings in Section 4.2 where the topic frequency of disaster reduction is considerable. The pollution and the air pollution in cities are caused mainly by public transportation means and cars. The network shows that there is a direct link between transport and air pollution in cities.

\section{Bigram Count Network}

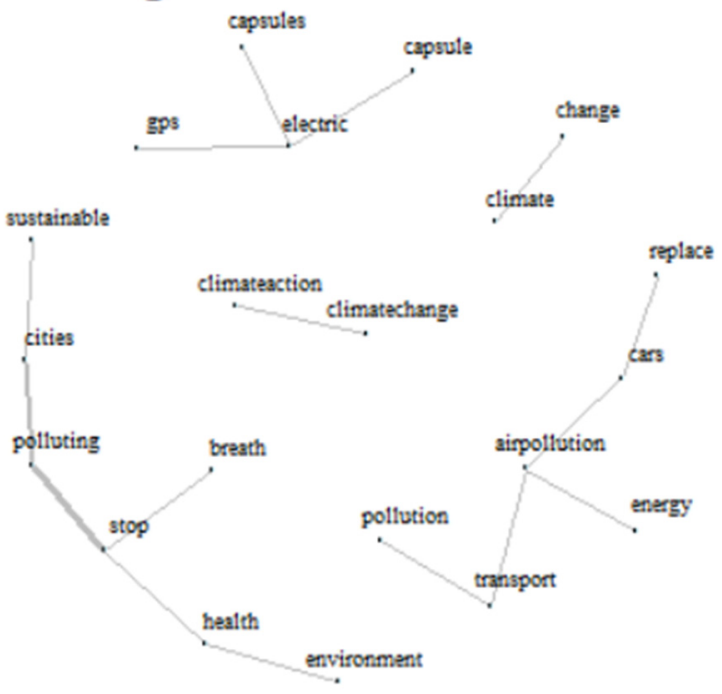

Figure 11. Bigram Network of SDG 11.

The expression "electrical capsule" occurred several times. This could be interpreted as a potential solution to save the environment and reduce pollution and air pollution in cities. In addition, there is a significant suggestion to replace cars and use electric capsules to save energy and the environment.

Our findings are consistent with previous research in the field. Domínguez et al. in [66] found that some Twitter influencers suggest the use of train instead of car, and pedestrianize the downtowns of cities in order to reduce gas emissions of cars. They suggested also reducing the use of cars on short trips, promoting walking and running for these trips. In the same vein, Bagliani et al. in [72] reported that transport, gas emissions and non-renewable energies are the main causes of air pollution. They advocated that the use of renewable energies could be a significant opportunity to achieve sustainability. Furthermore, Labonte and Rowlands in [68] studied Twitter-based conversations regarding energy issues and politics and showed, as we did in this study, that energy is linked with economic and environmental issues. Finally, Hamed and Zia in [73] used bigrams to analyze the climate change related discourse on Twitter and found that climate action and climate change are directly connected (as we depicted in Figure 11), and that pollution is linked to cities.

\section{Limitations of the Study}

This study has a set of limitations that we hereby present. First, there are limitations related to data. Our dataset is limited to Twitter, which may not reflect the overall public discourse related to SDGs in other social media platforms such as Facebook and Instagram. In addition, we restricted our study to English twitter posts, which may also limit our finding given the diversity of Twitter users in terms of identity and location.

Second, we have limitations related to Twitter API. For privacy issues, some users and tweets are deleted. When users delete tweets, they disappear from the APIs. In addition, due to Twitter API policy, the number of tweets requests is limited by time and by number. As a result, when collecting tweets, we are restricted to only the recent ones. 
Another limitation is that some user information such as the geolocation may be unavailable, so that we cannot use this information to cluster tweets by location.

Third, there are limitations related to the hashtags through which we extracted the tweets which refer to sustainable cities and SDG 11. In fact, there are few hashtags available in the web and in the literature that ae related to SDG 11. Therefore, we built in our research a list of hashtags using the description of SDG 11, including the general description of SDG 11 and the descriptions of topics and targets, as provided by the UN.

Finally, the context of the COVID-19 pandemic impacted the engagement of Twitter users to SDGs as the frequency of the tweets referring to SDG 11 decreased in 2020.

\section{Conclusions and Future Research Directions}

In this paper, we demonstrated how Twitter (as an Integrated Information Ecosystem) could be used to help policy makers which are hosting debates and setting priorities (political sphere) in identifying challenges regarding parameters of global sustainability (the sustainability sphere). To this end, we analyzed a set of tweets related to SDG 11 through three perspectives: Engagement analysis, Trends based analysis, and insights. Doing so, policy makers should be able to follow the evolution of the SDG 11 tweets over time to identify new emerging insights.

Our results about the engagement analysis enabled us to track the frequency of tweets related to SDG 11 over time and to highlight the most active users (which we can call influencers) interested in SDG 11. We observed that the creators of tweets are individuals or non-UN representatives than $\mathrm{UN}$ bodies and representatives. The trends-based analysis showed first that there are specific hashtags that we can find each year such as \#CSR, \#climateaction, or \#innovation. However, we observe other hashtags that were used only for a specific year such as the hashtag \#cop21 in 2015. We also observed the importance of hashtags related to artificial intelligence, IoT, or innovation that have been attracting more and more attention when talking about cities. Second, the trends-based analysis showed that the most discussed topics over the last six years are disaster risk reduction, sustainable cities, and human settlements. The data insights analysis showed that citizens are mostly concerned with issues related to the environment such as pollution and climate change.

For future research, we propose four directions. First, we can dig deeper into the data by doing a semantic analysis of the data by looking at the tweets contents and the hyperlinks in the tweets. Second, we propose conducting a field study to see how tweets data analysis can help them to build their SDGs policies for their cities. Third, it will be interesting to analyze tweets by integrating geolocation information. We can provide detailed insights on the discourse evolution in different cities and regions of the World. This can be informative so that cities can learn from each other. Finally, we propose to develop a dedicated platform for policymakers to present different facets of data analysis. By doing so, we will better inform them in regards to decision-making processes.

Author Contributions: Conceptualization, A.M., A.C., S.M. and R.H.; methodology, A.M., A.C., S.M. and R.H.; software, A.C.; validation, A.M., A.C., S.M. and R.H.; formal analysis, A.M., A.C., S.M. and R.H.; investigation, A.C. and A.M.; resources, A.M., A.C., S.M. and R.H.; data curation, A.C.; writing-original draft preparation, A.M. and A.C.; writing-review and editing, S.M. and R.H.; visualization, A.C., supervision, S.M. and R.H.; project administration, S.M.; funding acquisition, S.M. All authors have read and agreed to the published version of the manuscript.

Funding: This research received no external funding.

Institutional Review Board Statement: Not applicable.

Informed Consent Statement: Not applicable.

Data Availability Statement: Not applicable.

Conflicts of Interest: The authors declare no conflict of interest. 


\section{Appendix A. List of Hashtags}

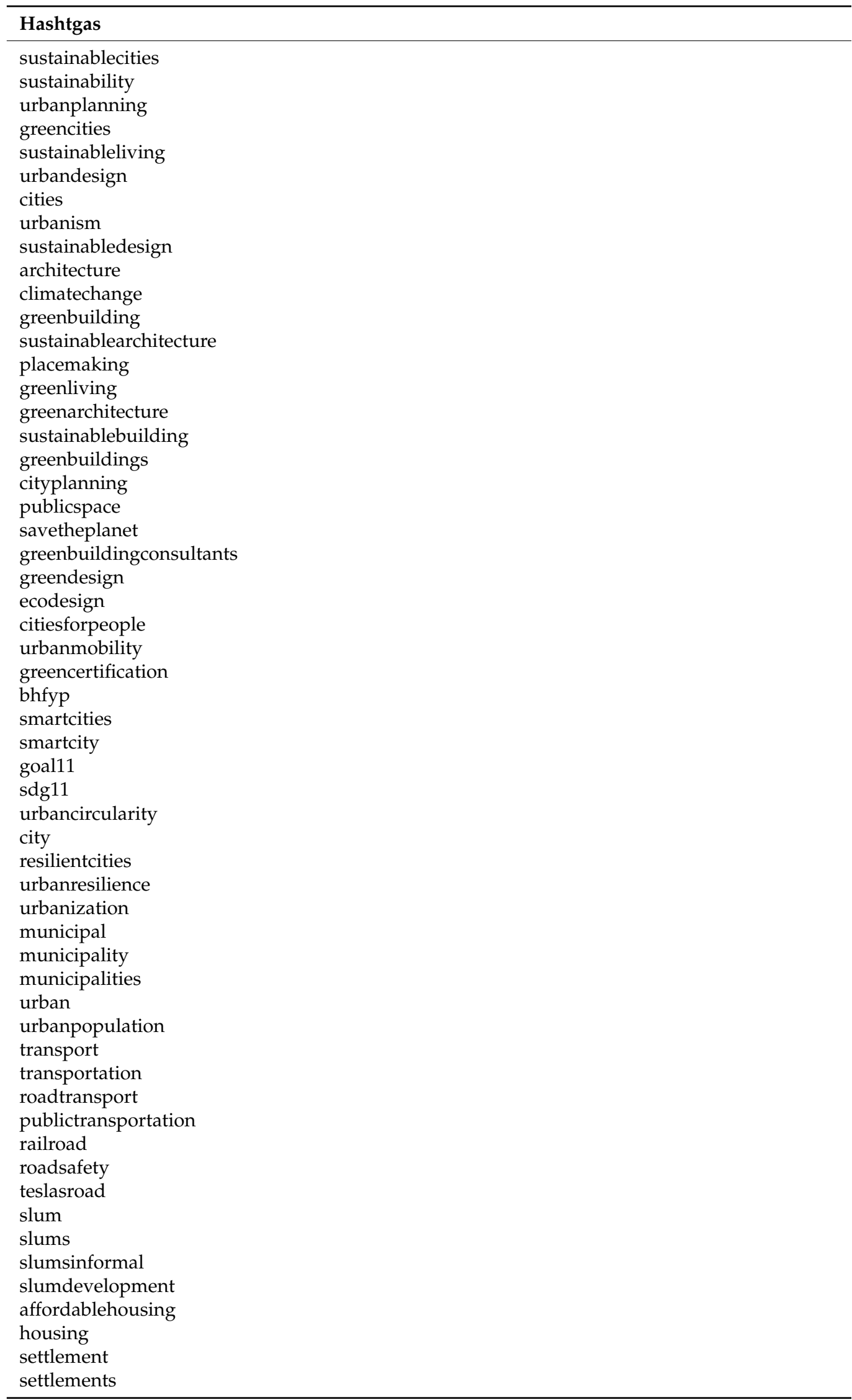




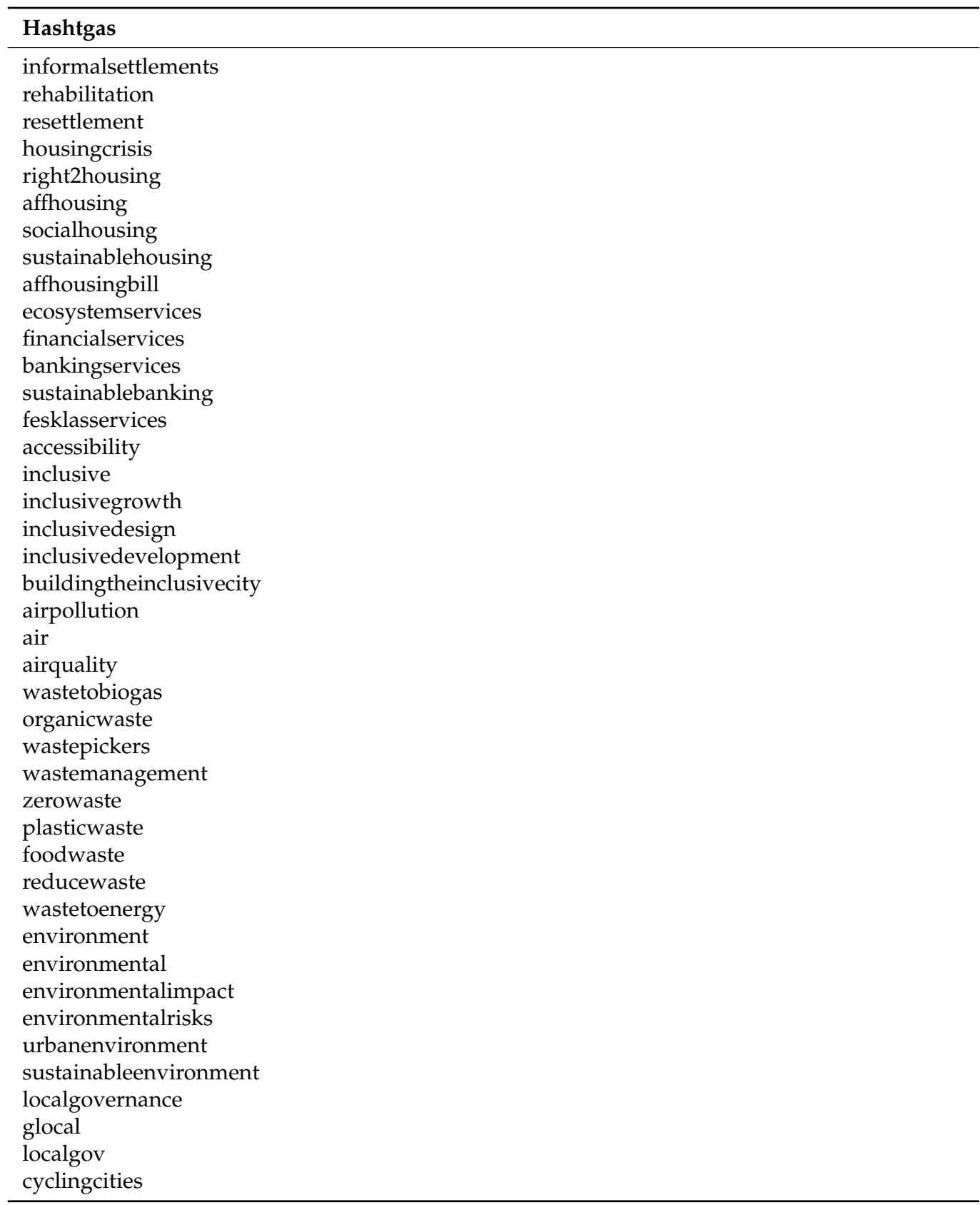

\section{References}

1. Pekmezovic, A. The UN and Goal Setting. In Sustainable Development Goals; Wiley: Hoboken, NJ, USA, $2019 ;$ pp. 17-35.

2. van Soest, H.L.; van Vuuren, D.P.; Hilaire, J.; Minx, J.C.; Harmsen, M.J.H.M.; Krey, V.; Popp, A.; Riahi, K.; Luderer, G. Analysing interactions among Sustainable Development Goals with Integrated Assessment Models. Glob. Transitions 2019, 1, $210-225$. [CrossRef]

3. Eremia, M.; Toma, L.; Sanduleac, M. The Smart City Concept in the 21st Century. Procedia Eng. 2017, 181, 12-19. [CrossRef]

4. United Nations. United Nations World Population Prospects. The 2015 Revision: Key Findings and Advance Table; United Nations: New York, NY, USA, 2015.

5. Dick, E. Urban Governance for Sustainable Global Development: From the SDGs to the New Urban Agenda. 2016, pp. 1-4. Available online: https:/ / www.econstor.eu/handle/10419/199772 (accessed on 28 March 2021).

6. Poon, L. What the UN's New Sustainable Development Goals Will (and Won't) Do for Cities-CityLab. Available online: https:/ / www.bloomberg.com/news/articles/2015-09-29/what-the-un-s-new-sustainable-development-goals-will-and-wont-do-for-cities (accessed on 28 March 2021).

7. Haughton, G. Environmental justice and the sustainable city. J. Plan. Educ. Res. 1999, 18, 233-243. [CrossRef]

8. Kenworthy, J.R. The eco-city: Ten key transport and planning dimensions for sustainable city development. Environ. Urban. 2006, 18, 67-85. [CrossRef] 
9. Koch, F.; Krellenberg, K. How to Contextualize SDG 11? Looking at Indicators for Sustainable Urban Development in Germany. ISPRS Int. J. Geo-Inf. 2018, 7, 464. [CrossRef]

10. Klopp, J.M.; Petretta, D.L. The urban sustainable development goal: Indicators, complexity and the politics of measuring cities. Cities 2017, 63, 92-97. [CrossRef]

11. Fitzgerald, J. Emerald Cities: Urban Sustainability and Economic Development; Oxford University Press: Oxford, UK, 2010.

12. Capello, R.; Camagni, R.; Nijkamp, P. Towards sustainable city policy: An economy-environment technology nexus. Ecol. Econ. 1998, 24. [CrossRef]

13. Ferrão, P.; Fernández, J.E. Sustainable Urban. Metabolism; MIT Press: Cambridge, MA, USA, 2013.

14. Easterly, W. The Trouble with the Sustainable Development Goals. Curr. Hist. 2015, 114, 322-324. [CrossRef]

15. Parnell, S. Defining a Global Urban Development Agenda. World Dev. 2016, 78, 529-540. [CrossRef]

16. Mistra Urban Futures. Rethinking Sustainable Cities: Accessible, Green and Fair; Policy Press: Bristol, UK, 2016; ISBN 9781447332855.

17. Patel, Z.; Greyling, S.; Simon, D.; Arfvidsson, H.; Moodley, N.; Primo, N.; Wright, C. Local responses to global sustainability agendas: Learning from experimenting with the urban sustainable development goal in Cape Town. Sustain. Sci. 2017, 12, 785-797. [CrossRef]

18. Marcotullio, P.J.; McGranahan, G. Scaling Urban. Environmental Challenges: From Local to Global and Back; Earthscan: London, UK, 2012; ISBN 9781849772471.

19. Shi, L.; Han, L.; Yang, F.; Gao, L. The Evolution of Sustainable Development Theory: Types, Goals, and Research Prospects. Sustainability 2019, 11, 7158. [CrossRef]

20. Dawes, S.S. The Evolution and Continuing Challenges of E-Governance. Public Adm. Rev. 2008, 68, S86-S102. [CrossRef]

21. Reyes-Menendez, A.; Saura, J.R.; Alvarez-Alonso, C. Understanding \#worldenvironmentday user opinions in twitter: A topicbased sentiment analysis approach. Int. J. Environ. Res. Public Health 2018, 15, 2537. [CrossRef]

22. Davis, K.E.; Kingsbury, B.; Merry, S.E. Introduction: The local-global life of indicators: Law, power, and resistance. In the Quiet Power of Indicators: Measuring Governance, Corruption, and Rule of Law; Cambridge University Press: Cambridge, UK, 2015; pp. 1-24. ISBN 9781139871532.

23. Kitchin, R.; Lauriault, T.P.; McArdle, G. Knowing and governing cities through urban indicators, city benchmarking and real-time dashboards. Reg. Stud. Reg. Sci. 2015, 2, 6-28. [CrossRef]

24. Thomas, R.; Hsu, A.; Weinfurter, A. Sustainable and inclusive-Evaluating urban sustainability indicators' suitability for measuring progress towards SDG-11. Environ. Plan. B Urban. Anal. City Sci. 2020, 239980832097540. [CrossRef]

25. Zinkernagel, R.; Evans, J.; Neij, L. Applying the SDGs to Cities: Business as Usual or a New Dawn? Sustainability $2018,10,3201$. [CrossRef]

26. Arslan, T.V.; Durak, S.; Aytac, D.O. Attaining SDG11: Can sustainability assessment tools be used for improved transformation of neighbourhoods in historic city centers? Nat. Resour. Forum 2016, 40, 180-202. [CrossRef]

27. OECD. Competitive Cities in the Global Economy; OECD: Paris, France, 2006; ISBN 92-64-02708-4.

28. WCED. Our common future. In World Commission on Enironment and Development; Brundtland Commission: Rio de Janeiro, Brazil, 1987; pp. 1-91.

29. Abastante, F.; Lami, I.M.; Gaballo, M. Pursuing the SDG11 Targets: The Role of the Sustainability Protocols. Sustainability 2021, 13, 3858. [CrossRef]

30. Satterthwaite, D. Sustainable Cities or Cities that Contribute to Sustainable Development? Urban. Stud. 1997, 34, 1667-1691. [CrossRef]

31. MacDonald, A.; Clarke, A.; Huang, L. Multi-stakeholder Partnerships for Sustainability: Designing Decision-Making Processes for Partnership Capacity. J. Bus. Ethics 2019, 160, 409-426. [CrossRef]

32. Corbett, J.; Mellouli, S. Winning the SDG battle in cities: How an integrated information ecosystem can contribute to the achievement of the 2030 sustainable development goals. Inf. Syst. J. 2017, 27, 427-461. [CrossRef]

33. Saner, R.; Yiu, L.; Nguyen, M. Monitoring the SDGs: Digital and social technologies to ensure citizen participation, inclusiveness and transparency. Dev. Policy Rev. 2020, 38, 483-500. [CrossRef]

34. United Nations Development Group. A Million Voices: The World We Want; UNDG: New York, NY, USA, 2013 ; Volume 172.

35. Walker, D.W. Citizen-driven reform of local-level basic services: Community-Based Performance Monitoring. Dev. Pract. 2009, 19, 1035-1051. [CrossRef]

36. Mergel, I. A framework for interpreting social media interactions in the public sector. Gov. Inf. Q. 2013, 30, 327-334. [CrossRef]

37. Vaast, E.; Kaganer, E. Social media affordances and governance in the workplace: An examination of organizational policies. J. Comput. Commun. 2013, 19, 78-101. [CrossRef]

38. Zheng, L.; Zheng, T. Innovation through social media in the public sector: Information and interactions. Gov. Inf. Q. 2014, 31, S106-S117. [CrossRef]

39. Kavanaugh, A.; Tedesco, J.C.; Madondo, K. Social media vs. Traditional internet use for community involvement: Toward broadening participation. In Proceedings of the Lecture Notes in Computer Science (Including Subseries Lecture Notes in Artificial Intelligence and Lecture Notes in Bioinformatics), Santiago, Chile, 7-10 September 2014; Volume 8654, pp. 1-12.

40. Kim, B.J.; Kavanaugh, A.L.; Hult, K.M. Civic Engagement and Internet Use in Local Governance. Adm. Soc. 2011, 43, 807-835. [CrossRef] 
41. Meijer, A.J. Networked Coproduction of Public Services in Virtual Communities: From a Government-Centric to a Community Approach to Public Service Support. Public Adm. Rev. 2011, 71, 598-607. [CrossRef]

42. Boudjelida, A.; Mellouli, S.; Lee, J. Electronic citizens participation: Systematic review. In Proceedings of the 9th International Conference on Theory and Practice of Electronic Governance, Montevideo, Uruguay, 1-3 March 2016; Association for Computing Machinery: New York, NY, USA, 2016; Volume 1, pp. 31-39.

43. Killian, S.; Lannon, J.; Murray, L.; Avram, G.; Giralt, M.; O’Riordan, S. Social Media for Social Good: Student engagement for the SDGs. Int. J. Manag. Educ. 2019, 17, 100307. [CrossRef]

44. Chouikh, A.; Ojo, A.; Driss, O.B. Exploring the Affordances of Social Media Platforms in Supporting Emerging Public Service Paradigms. In Proceedings of the 9th International Conference on Theory and Practice of Electronic Governance, Montevideo, Uruguay, 1-3 March 2016; ACM Press: New York, NY, USA, 2016; Volume 1, pp. 177-186.

45. Ekenga, C.; McElwain, C.-A.; Sprague, N. Examining Public Perceptions about Lead in School Drinking Water: A Mixed-Methods Analysis of Twitter Response to an Environmental Health Hazard. Int. J. Environ. Res. Public Health 2018, 15, 162. [CrossRef]

46. Rathod, T.; Barot, M. Trend Analysis on Twitter for Predicting Public Opinion on Ongoing Events. Int. J. Comput. Appl. 2018, 180, 13-17. [CrossRef]

47. Puschmann, C.; Burgess, J. The Politics of Twitter Data. SSRN Electron. J. 2013. [CrossRef]

48. Stieglitz, S.; Dang-Xuan, L. Social media and political communication: A social media analytics framework. Soc. Netw. Anal. Min. 2013, 3, 1277-1291. [CrossRef]

49. Zhou, R.; Khemmarat, S.; Gao, L. The Impact of YouTube Recommendation System on Video Views. Proc. 10th ACM Sigcomm. Conf. Internet Meas. 2010, 404-410. [CrossRef]

50. Leonhardt, J.M. Tweets, hashtags and virality: Marketing the Affordable Care Act in social media. J. Direct Data Digit. Mark. Pract. 2015, 16, 172-180. [CrossRef]

51. Hönings, H.; Knapp, D.; Nguyễn, B.C.; Richter, D.; Williams, K.; Dorsch, I.; Fietkiewicz, K.J. Health information diffusion on Twitter: The content and design of WHO tweets matter. Health Inf. Libr. J. 2021. [CrossRef]

52. Kumar, S.; Morstatter, F.; Liu, H. Twitter Data Analytics; Springer: Berlin, Germany, 2014; p. 89.

53. Anber, H.; Salah, A.; El-Aziz, A.A.A. A Literature Review on Twitter Data Analysis. Int. J. Comput. Electr. Eng. 2016, 8, 241-249. [CrossRef]

54. Thelwall, M. Word Association Thematic Analysis: A Social Media Text Exploration Strategy. Synth. Lect. Inf. Concepts Retr. Serv. 2021, 13, 1-111.

55. Ishikawa, H. Social Big Data Mining; CRC Press: Boca Raton, FL, USA, 2015; ISBN 9781498710947.

56. Boot, A.B.; Tjong Kim Sang, E.; Dijkstra, K.; Zwaan, R.A. How character limit affects language usage in tweets. Palgrave Commun. 2019, 5, 76. [CrossRef]

57. Bali, R.; Sarkar, D.; Sharma, T. Learning Social Media Analytics with R: Transform. Data from Social Media Platforms into Actionable Insights; Packt Publishing: Birmingham, UK, 2017; ISBN 9781787127524.

58. Gull, R.; Shoaib, U.; Rasheed, S.; Abid, W.; Zahoor, B. Pre Processing of Twitter's Data for Opinion Mining in Political Context. Procedia Comput. Sci. 2016, 96, 1560-1570. [CrossRef]

59. ElAlfy, A.; Darwish, K.M.; Weber, O. Corporations and sustainable development goals communication on social media: Corporate social responsibility or just another buzzword? Sustain. Dev. 2020, 28, 1418-1430. [CrossRef]

60. Wang, Z.; Hahn, K.; Kim, Y.; Song, S.; Seo, J.-M. A news-topic recommender system based on keywords extraction. Multimed. Tools Appl. 2018, 77, 4339-4353. [CrossRef]

61. Aman, M.; bin Md Said, A.; Jadid Abdul Kadir, S.; Ullah, I. Key Concept Identification: A Comprehensive Analysis of Frequency and Topical Graph-Based Approaches. Information 2018, 9, 128. [CrossRef]

62. Joshi, R.; Tekchandani, R. Comparative analysis of Twitter data using supervised classifiers. In Proceedings of the 2016 International Conference on Inventive Computation Technologies (ICICT), Coimbatore, India, 26-27 August 2016; Volume 2016, pp. 1-6.

63. Lwin, M.O.; Lu, J.; Sheldenkar, A.; Schulz, P.J.; Shin, W.; Gupta, R.; Yang, Y. Global Sentiments Surrounding the COVID-19 Pandemic on Twitter: Analysis of Twitter Trends. JMIR Public Health Surveill. 2020, 6, e19447. [CrossRef] [PubMed]

64. Chen, E.; Lerman, K.; Ferrara, E. Tracking Social Media Discourse About the COVID-19 Pandemic: Development of a Public Coronavirus Twitter Data Set. J. Med. Internet Res. 2020, 6, e19273. [CrossRef] [PubMed]

65. Pilař, L.; Kvasničková Stanislavská, L.; Pitrová, J.; Krejčí, I.; Tichá, I.; Chalupová, M. Twitter Analysis of Global Communication in the Field of Sustainability. Sustainability 2019, 11, 6958. [CrossRef]

66. Caldevilla-Domínguez, D.; Barrientos-Báez, A.; Padilla-Castillo, G. Twitter as a tool for citizen education and sustainable cities after COVID-19. Sustainability 2021, 13, 3514. [CrossRef]

67. Kumar, A.; Nagar, S.; Anand, S. Climate change and existential threats. Glob. Clim. Chang. Elsevier 2021, 1-31. [CrossRef]

68. Labonte, D.; Rowlands, I.H. Tweets and transitions: Exploring Twitter-based political discourse regarding energy and electricity in Ontario, Canada. Energy Res. Soc. Sci. 2021, 72, 101870. [CrossRef]

69. Reining, P.C. Village Viability in Contemporary Society; Routledge: Oxfordshire, UK, 2019.

70. Kulkki, S. Cities for Solving Societal Challenges towards Human-centric Socio-economic Development? Interdiscip. Stud. J. 2014, $3,8-14$. 
71. Haro-de-Rosario, A.; Sáez-Martín, A.; del Carmen Caba-Pérez, M. Using social media to enhance citizen engagement with local government: Twitter or Facebook? New Media Soc. 2018, 20, 29-49. [CrossRef]

72. Bagliani, M.; Dansero, E.; Puttilli, M. Territory and energy sustainability: The challenge of renewable energy sources. J. Environ. Plan. Manag. 2010, 53, 457-472. [CrossRef]

73. Hamed, A.A.; Zia, A. Mining Climate Change Awareness on Twitter: A PageRank Network Analysis Method. In Lecture Notes in Computer Science (Including Subseries Lecture Notes in Artificial Intelligence and Lecture Notes in Bioinformatics); Springer: Berlin, Germany, 2015; Volume 9155, pp. 16-31. ISBN 9783319214030. 